\title{
Update of the therapeutic planning of irrigation and intracanal medication in root canal treatment. A literature review
}

\author{
Ilaria Prada ${ }^{1}$, Pedro Micó-Muñoz ${ }^{2}$, Teresa Giner-Lluesma ${ }^{3}$, Pablo Micó-Martínez ${ }^{4}$, Susana Muwaquet-Rodríguez ${ }^{3}$, \\ Alberto Albero-Monteagudo ${ }^{3}$ \\ ${ }^{1}$ Licensed Dentist at Universidad Europea de Valencia, España \\ ${ }^{2}$ Endodontic and restorative dentistry Titular Professor, Universidad Europea de Valencia, España \\ ${ }^{3}$ Endodontic and restorative dentistry Associated Professor, Universidad Europea de Valencia, España \\ ${ }^{4}$ Licensed Dentist at Universidad Europea de Valencia. Periodontology and Osteointegration Master at Universidad de Valencia, \\ España
}

Correspondence:

Calle Literato Gabriel Miro 34-4-11

46008 Valencia (ES)

ilaria.prada94@gmail.com

Received: 08/01/2019 Accepted: $21 / 01 / 2019$

Prada I, Micó-Muñoz P, Giner-Lluesma T, Micó-Martínez P, Muwaquet-Rodríguez S, Albero-Monteagudo A. Update of the therapeutic planning of irrigation and intracanal medication in root canal treatment. A literature review. J Clin Exp Dent. 2019;11(2):e185-93.

http://www.medicinaoral.com/odo/volumenes/v11i2/jcedv11i2p185.pdf

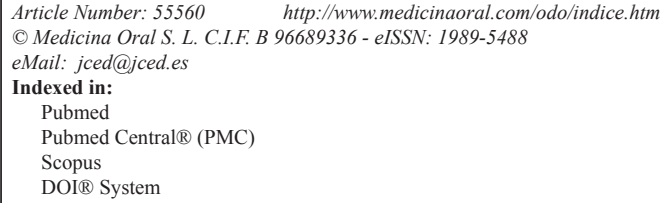

\begin{abstract}
Background: The success of endodontic treatment derives from the complete elimination of microorganisms capable of causing an intraradicular or extraradicular infection. To achieve a more effective eradication of these microorganisms, endodontic instrumentation must always be implemented with abundant irrigation, which has to achieve chemical, mechanical and biological effects. The irrigators most used today are $\mathrm{NaOCl,} \mathrm{CHX} \mathrm{and} \mathrm{EDTA,}$ released into the ducts through different techniques such as syringe, manual agitation, positive or negative apical pressure, sonic or ultrasonic activation, PIPS and PDT. The objective of this review is to update the different irrigating solutions and intracanal disinfection drugs, as well as to establish an irrigation protocol in the endodontic treatment.

Material and Methods: Systematic search of scientific articles in the databases PubMed, Medline and Google Scholar, with the following keywords Endodontic, Infection, Failure, Irrigation, Retreatment and Irrigation protocol. The exclusion criteria were "case report" articles and articles with a publication date prior to 2000 .

Results: 48 articles that met the inclusion criteria were analyzed. Comparing the different articles it can be seen that the $\mathrm{NaOCl}$ is the "gold standard" in terms of immediate antimicrobial efficacy, followed by the CHX that has a long-term antibacterial effect. As an intra-conductive drug it is advisable to use the combination of $\mathrm{Ca}(\mathrm{OH})_{2}$ with CPMC.

Conclusions: The most adequate irrigation protocol consists of using $2.5 \% \mathrm{NaOCl}$ activated with ultrasound followed by a final wash with $7 \%$ MA or $0.2 \%$ CTR combined with $2 \%$ CHX.
\end{abstract}

Key words: Endodontic failure, endodontic infection, enterococcus faecalis, endodontic retreatment, irrigation, sodium hipoclorite, irrigation protocol. 


\section{Introduction}

The success of root canal treatment depends on a correct chemomechanical disinfection to eliminate the pulp tissue, the remains of dentin and microorganisms, thus eliminating the etiological factors that cause the endodontic infection. Therefore, the instrumentation of the root canals must always be accompanied by irrigation to remove the remains of pulp tissue and dentin. Without irrigation, remains of material would accumulate causing the instruments to become ineffective (1).

The effects to be achieve with irrigation in endodontics are mainly three:

Chemicals: dissolution of organic and inorganic tissue, removal of dentine and smear layer residues. These effects can be expected only from chemically active irrigators (sodium hypochlorite, EDTA) (2).

Mechanics: lubrication of the duct, mechanical removal of microorganisms/biofilms, pulp tissue remnants, as well as the remains of dentin thanks to the forces applied by the flow of the irrigant. These effects can be expected both from chemically active irrigators (sodium hypochlorite) and from inert irrigants (water, saline) (2). Biological: efficacy against anaerobic and facultative microorganisms, eradication or inactivation of biofilm, inactivation of endotoxins (3).

The classification of the irrigating solutions are summarized in Table 1 (1).
The syringe release consists of transporting the solution to the canal by means of a syringe, which serves to introduce it accurately, replace the liquid, eliminate large residual particles and allow direct contact with microorganisms in the areas where the needle tip arrives. In addition, for disinfectants to effectively reach the full length of the canal, it is advisable to perform coronoapical movements with the irrigation needle or shaking movements with small endodontic instruments or push-pull manual movements with a gutta-percha cone (6).

Irrigation with negative pressure is used in order to improve the access of the irrigating solution. The technique consists in applying the irrigant in the access chamber and in the root canal a very fine needle is placed which is connected to the suction device of the dental unit. Thanks to the pressure created, the excess of the irrigating solution placed in the access cavity is displaced apically and is eliminated through the suction device. This system is marketed under the name of EndoVac ${ }^{\circledR}$ (5).

Recently, in view of the need to improve the disinfection of the root canals, irrigation techniques have emerged whose system is based on the agitation of the irrigant in order to improve its diffusion and activity (6).

The sonically activated irrigation, represented mainly by the EndoActivator ${ }^{\circledR}$, uses tips that are passively activated at 10,000 cycles / minutes for 30-60 seconds. In contrast, ultrasonic devices require vibrations greater than

Table 1: Ideal endodontic irrigation solution characteristics.

\begin{tabular}{|l|c|c|}
\hline \multirow{2}{*}{ Tissue dissolving agents } & Chemical agents & Natural agents \\
\hline Anitbacterial agents & NaOCl & \\
\cline { 2 - 2 } & Bacteriostatic: $\mathrm{CHX}$, some ATB & \multirow{2}{*}{$\begin{array}{c}\text { Green tea, Triphala, } \\
\text { Curcuma Longa }\end{array}$} \\
\hline Chelating agents & Mild pH: HEBP & \\
\cline { 2 - 2 } & Strong Ph: EDTA & \\
\hline Product combination & MTDA. QMiX, SmearClear, Tetraclean & \\
\hline
\end{tabular}

One of the biggest challenges of irrigation is that it has to reach areas that the mechanical instrumentation with files does not reach, that is, the isthmus, the lateral ducts, the apical deltas, the outermost portions of the oval ducts, etc.; in fact, it is well documented that between $35 \%$ and $53 \%$ of the walls of the ducts remain uninstrumented (4). Therefore, microorganisms located in these portions have a greater chance of survival (3). So the only way to eliminate the remains of tissue and microorganisms that remain in these areas is through chemical preparation with irrigants (1).

For a correct irrigation, a fundamental factor is the volume of the irrigant, the greater the volume, the greater the cleaning. Therefore, different and numerous methods of application and agitation of irrigating substances have been developed (5).
$20,000 \mathrm{~Hz}$ to give rise to the cavitation effect that allows the disinfection of the root canals (5).

The Photon Induced Photoacoustic Streaming (PIPS) is a new technique of laser agitation, erbium laser: garnet yttrium and alumina (ER: YAG), which has been proven effective for the debridement and the elimination of the smear layer, thanks to its novel design. The technique consists of placing the laser tip only in the pulp chamber without deepening to the root canal (7). This technique, to guarantee the activation of the irrigant, does not need the tips to move inside the ducts, but it is the photo acoustic shock wave, created by the laser effect, which activates the irrigating solution and causes its three-dimensional movement in the duct system (8).

Photodynamic therapy (PDT) uses a photosensitizer (PS) that is applied in selected tissues and consists of a 
dye, such as malachite green, which is fixed to oral microorganisms; when the PS is exposed to a specific wavelength, low-power laser light is excited and produces a series of transferences of molecular energy that result in the release of oxygen ions and free radicals, which being highly reactive and cytotoxic, they produce cell death (9).

The most known and used irrigating agents today are sodium hypochlorite $(\mathrm{NaOCl})$, chlorhexidine $(\mathrm{CHX})$ and ethylenediaminetetracetic acid (EDTA). None of these substances is the ideal irrigator, all have advantages and disadvantages, and because of this it is convenient to use them in combination. The market is always launching new compounds or new alternatives to enhance the effects of existing irrigants. It would therefore be interesting to compare the efficacy of the old and new irrigants on the endodontic microbiota and to see if one method is more effective than another when eradicating the bacterial biofilm, until an ideal protocol of action is determined.

The objectives of this bibliographical review are to compare the different therapeutic alternatives of irrigation and available intracanal drugs and to establish the most effective irrigation protocol nowadays.

\section{Material and Methods}

The article search was carried out by one researcher in the following databases:

Pubmed: the keywords used, combined between them, Endodontic, Infection, Enterococcus faecalis, Failure, Irrigation, Retreatment, united by the Boolean AND and limiting the search field of these words in the title and in the abstract. This search gave us a total result of 1245 articles.

Medline: this search was carried through the Discover library of the European University of Valencia using these keywords: Endodontic irrigation and Retreatment, united by the Boolean AND. This search gave us a total result of 20 articles.

Google Scholar: to perform the search, the following phrase was used: Irrigation protocol in endodontics retreatment. This search gave us a total result of 2070 articles.

The inclusion criteria for the articles selection were: Articles published after 2000, "full text" articles, journal articles with an "impact factor" greater than 1, literature review articles and research articles.

"Case report" articles and articles with publication date prior to 2000 were excluded.

A total of 3335 articles have been initially located. Many of these, 1927, were duplicated in the different databases, therefore, they were eliminated, reaching a total of 1408 articles. Reading the title of each article, taking into account the objectives of the work, another 1175 records were eliminated, thus reaching a total of 233 articles. Of these, the summary was read and 135 others were eliminated that were not considered relevant for the review. Finally, 98 articles were left for the full-text review; of these, 63 articles were excluded for not complying with the inclusion parameters. To these articles were added another 13 extracted from the manual search.

The articles taken into consideration were finally 48 .

\section{Results and Discussion}

-Irrigation-disinfection materials

A successful endodontic treatment or retreatment is based on the combination of adequate instrumentation, irrigation and obturation of the duct system. Of these three phases, irrigation is the most important determinant when promoting the healing of pulp-periapical pathologies. This is so, because the irrigant can remove the remains of necrotic tissue and disinfect the ducts, favoring the elimination or reduction of the bacteria, especially in those teeth with complex internal anatomy. To date, a large variety of irrigant has been used for this purpose, with $\mathrm{NaOCl}$ being the gold standard (1). In fact, the study by Giardino et al. (10), in 2007, carried out to evaluate the antimicrobial efficacy of $5.25 \%$ of $\mathrm{NaOCl}$, of Tetraclean ${ }^{\circledR}$ (a mixture of doxycycline, citric acid and detergents) and of MTAD ${ }^{\circledR}$ (a mixture of doxycycline, citric acid and detergents), confirmed the supremacy of $\mathrm{NaOCl}$, since it was the only irrigator able to remove the entire biofilm after $5 \mathrm{~min}$. In the same

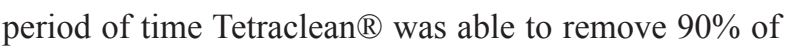
the biofilm, reaching $99.9 \%$ after $30 \mathrm{~min}$ and $100 \%$ at $60 \mathrm{~min}$; whereas MTAD ${ }^{\circ}$ was never able to completely eradicate biofilm (10). However, two years later, the same authors compared the effects of $5.25 \% \mathrm{NaO}$ $\mathrm{Cl}$, Tetraclean ${ }^{\circledR}$, Cloreximid ${ }^{\circledR}$ (a mixture of $\mathrm{CHX}$ and Cetrimide) and MTAD ${ }^{\circledR}$ against two different bacterial groups: bacteria strict anaerobes, represented by Prevotella and by Porphyromonas, and facultative anaerobic bacteria. In the first group, $\mathrm{NaOCl}$ was more effective, with statistically significant differences compared to the other irrigants, while $\mathrm{NaOCl}$ was not equally effective against $E$. faecalis, being overcome, with statistically significant differences, by MTAD ${ }^{\circledR}$ and Tetraclean ${ }^{\circledR}$ that led to wider zones of inhibition. Cloreximid ${ }^{\circledR}$, in both groups, was the one that showed the least antibacterial action (11).

Completely opposite are the results obtained by Dunavant et al. (12) in 2006 that placed the MTAD ${ }^{\circledR}$ in last position with a $16 \%$ lethality against $E$. faecalis; probably these results are due to the fact that the study by Giardino et al. (11) has been carried out on planktonic cells of E. faecalis, while the study by Dunavant et al. (12) was on biofilms of the same bacteria. These authors determined that the most effective antimicrobial agent is $1 \%$ and $6 \% \mathrm{NaOCl}$, without statistically significant differences between the two concentrations but between 
the same and the other irrigants analyzed: Smear Clear ${ }^{\circledR}$ (a mixture of EDTA, Cetrimide and polyoxyethylene), CHX, REDTA $\AA$ and MTAD $\AA$, which achieved a case-fatality rate of $78 \%, 60 \%, 26 \%$ and $16 \%$ respectively (12). In contrast, in the study by Gomes et al. (13), in 2001, the three irrigating solutions that led most rapidly $(<30$ s) to the elimination of $100 \%$ of E. faecalis were $5.25 \%$ of $\mathrm{NaOCl}$ and the $\mathrm{CHX}$ liquid at $1 \%$ and $2 \%$, with statistically significant differences with respect to the other concentrations of $\mathrm{NaOCl}$ and the $\mathrm{CHX}$ in gel. On the other hand, Menezes et al. (14), in 2004, determined that a concentration of $2.5 \%$ of $\mathrm{NaOCl}$ is not capable of completely eliminating $E$. faecalis, being the antibacterial efficacy obtained by this irrigant statistically inferior to $\mathrm{CHX}$ at $2 \%$. However, the same two irrigants work equally well against $C$. albicans since no results were obtained with statistically significant differences (14). Completely opposite were the results obtained by Hope et al. (15) in 2010. In effect, they determined that $1 \%$ of $\mathrm{NaOCl}$ has a higher lethality, with statistically significant differences, against $E$. faecalis, compared with $2 \%$ of CHX and the super-oxidized water. However, CHX is significantly more effective than super-oxidized water. The effectiveness of $2 \%$ of $\mathrm{CHX}$ is also confirmed by the study by Endo et al. (16), which states that an instrumentation accompanied by an irrigation with $\mathrm{CHX}$ eliminates $99.61 \%$ of the bacteria. A feature that makes CHX so effective against $E$. faecalis may be its ability to decrease adhesion of the bacteria to dentinal walls (17). In fact, when the CHX is used as the last irrigant, the number of bacteria that remain attached to the surface of the root canals is $19-28 \%$ compared to when EDTA or $\mathrm{NaOCl}$ are the last, respectively with $67 \%$ and 40 $49 \%$ of attached bacteria (17). Because EDTA is a chelating agent that opens the dentinal tubules and exposes collagen, some authors believe that this action favors bacterial colonization (17) while other authors investigate this substance, as do the other chelating substances (phosphoric acid, citric acid), to be used as an antimicrobial agent (18). Undoubtedly, in the end, it turns out that EDTA does not possess any antimicrobial action against E. faecalis even after leaving it for 60 minutes; on the other hand, $2.5 \%$ phosphoric acid used 5 min to eliminate E. faecalis and 5\% $3 \mathrm{~min}$, and citric acid 25\% $3 \mathrm{~min}$ and $10 \% 10 \mathrm{~min}(18)$. Another study that highlights the ineffectiveness of EDTA is that of Baca et al. (19) in 2011. Comparing the antimicrobial efficacy of $17 \%$ of EDTA with that of $2.5 \%$ of $\mathrm{NaOCl}$, of $0.2 \%$ of cetrimide (CTR), of $7 \%$ of maleic acid (MA) and $2 \%$ CHX, it was found that EDTA eradicates only $44 \%$ of the biofilm with statistically significant differences with respect to the other groups. The irrigator that obtained better results is $2.5 \%$ of $\mathrm{NaOCl}$ that only after 1 min eradicated $100 \%$ of bacteria, but without showing statistically significant differences with the CTR; however, CHX and
MA eliminated $99 \%$ of the biofilm without statistically significant differences between them (19). Ferrer and Arias (20), in 2010, lowering the MA concentration to $0.88 \%$, discovered that it is capable of completely eradicating E. faecalis after $30 \mathrm{~s}$; the same result is obtained if $7 \% \mathrm{MA}$ is combined with $0.2 \% \mathrm{CTR}$; on the other hand, if $0.2 \%$ CTR is combined with $15 \%$ citric acid or EDTA, E. faecalis is eradicated in $1 \mathrm{~min}$, without statistically significant differences between the two combinations. These results underscore the ability of MA to eliminate E. faecalis not only at the recommended concentration of $7 \%$ but also at a much lower concentration, $0.88 \%$. Its antimicrobial activity may be due to its chemical nature of organic acid; organic acids lower the internal $\mathrm{pH}$ of the microbial cells by altering the permeability of the membranes (20).

In addition to the irrigating solutions necessary to carry out a correct chemo-mechanical instrumentation, in the ducts can also be introduced, especially in cases of endodontic failure, drugs such as $\mathrm{Ca}(\mathrm{OH})_{2}$; however, there are controversial opinions on its use and efficacy, given that microorganisms often turn out to be resistant to this disinfection measure (21). However, the study by Evans et al. (22), in 2002, underlines the importance of $\mathrm{Ca}(\mathrm{OH})_{2}$ : in fact, after having exposed E. faecalis to $\mathrm{Ca}(\mathrm{OH})_{2}$ with a $\mathrm{pH}$ of 11.1 , has been seen that only $0.4 \%$ of microorganisms survive; undoubtedly, increasing the $\mathrm{pH}$ to 11.5 also increases the lethality, reaching $99.9 \%$ (22). In contrast, the study by Beus et al. (23), in 2012, concludes that $\mathrm{Ca}(\mathrm{OH})_{2}$ is not strictly necessary and useful when it comes to reducing bacterial contamination of the root canals, given that the differences in the results obtained before and after the placement of intracanal medication are not statistically significant, with negative cultures being pre-medication of $82 \%$ and post-medication of $87 \%$. The same results are also obtained by Endo et al. (16), in 2013, who concluded that there are no statistically significant differences between the samples taken after the instrumentation and after the placement of the intracanal drugs. They also found that there are no statistically significant differences between the different groups of drugs analyzed, the $\mathrm{Ca}(\mathrm{OH})_{2}+\mathrm{CHX}$ at $2 \%$, which led to a decrease of the colony forming units (CFU) of $99.86 \%, \mathrm{Ca}(\mathrm{OH})_{2}+\mathrm{NaOCl}$ at $0.9 \%$ with a decrease of $99.6 \%$ and CHX at $2 \%$ with $99.57 \%$ (16). It has been seen that CHX is capable of conferring a greater antimicrobial action when several intracanal drugs are combined. In fact, in the study of Lima and Siqueira, in 2001, they saw that, among all the groups of drugs analyzed, only those containing CHX were capable of completely eliminating the biofilm of E. faecalis (24). In particular, those with greater antimicrobial efficacy with statistically significant differences with respect to the other groups were $2 \%$ of CHX with $2 \%$ of Natrozol, $2 \%$ of CHX with $1.25 \%$ of sodium lauryl sulfate and $2 \%$ 
of Natrozol, and $2 \%$ of CHX with $15 \%$ of zinc oxide, $1.25 \%$ of sodium lauryl sulfate and $2 \%$ of Natrozol (24). In addition to combining several drugs already known, it has been tried to introduce alternative drugs such as Tricresolformalin, canforated paramonochlorophenol (CPMC) and furacine paramonochlorophenol (FPMC). However, it has been seen that against Candida albicans Tricresol is the least effective medicine, since it leaves between 400 and $500 \mathrm{CFU}$, with statistically significant differences with respect to $\mathrm{Ca}(\mathrm{OH})_{2}, \mathrm{CPMC}, \mathrm{Ca}(\mathrm{OH})_{2}$ + CPMC and FPMC. For E. faecalis, however, the least effective drug is FPMC with statistically significant differences with respect to $\mathrm{Ca}(\mathrm{OH})_{2}+\mathrm{CPMC}$. Therefore, a valid alternative to $\mathrm{Ca}(\mathrm{OH})_{2}$ alone is to combine it with CPMC, a phenolic compound that has bactericidal activity since it breaks cytoplasmic membranes, denatures proteins and inactivates enzymes (14). Also Siqueira et al. (25), in 2007, confirmed that the combination of $\mathrm{Ca}(\mathrm{OH})_{2}$, with the CPMC paste, placing it for 7 days, increases the number of negative cultures to $90.9 \%$ with statistically significant differences with respect to pre and post instrumentation cultures. In addition, in the same year, the same author (26) determines that the $\mathrm{Ca}(\mathrm{OH})_{2}$ used alone does not give statistically significant results, given that the percentage of negative cultures after instrumentation is $54.5 \%$ and the post medication is 81.8 . \%. The ineffectiveness of $\mathrm{Ca}(\mathrm{OH})_{2}$ alone is also confirmed in the Siqueira and Rocas study of 2001 (27). Indeed, comparing the antifungal activity of different drugs, it turns out that the most effective are calcium sulfate combined with $\mathrm{CPMC}$ and $\mathrm{Ca}(\mathrm{OH})_{2}$ always combined with CPMC, which exceed, with statistically significant differences, $\mathrm{Ca}(\mathrm{OH})_{2}$ alone and calcium sulfate alone, which has no inhibitory properties (27). A substitute option for $\mathrm{Ca}(\mathrm{OH})_{2}$ may be the ozone oil proposed by Silveira and Siqueira in 2017 (28). Ozone owes its bactericidal, virucidal and sporicidal activity to its ionizing properties. The hydrolysis of the ozone oil can generate hydrogen peroxide, which causes the rupture of the cytoplasmic membrane, the oxidation of the enzymes and the damage to DNA, aldeides and ketones, which inhibit the metabolism of the bacteria and favor the rupture of the cytoplasmatic membrane, thus leaving the intracellular constituents. The success rates of teeth treated with this therapy are $77 \%$, results comparable to those obtained by the CPMC, with $74 \%$, and with statistically significant differences with respect to those teeth that were treated in a single visit, with a success rate of $46 \%$. Therefore, ozone oil can be a valid alternative to the common intracanal medications (28).

A very important factor that must be taken into consideration when choosing which irrigants to use during the preparation of the root canals is the substantivity, that is, the ability of the irrigating agent to continue exercising its antimicrobial action over time. This property is typi- cal of the CHX which, thanks to its cationic nature, is able to adhere to the surfaces of the entire canal system and remain stored there releasing slowly (1). Numerous, therefore, are the studies that test its antimicrobial efficacy in the long term. One of these is that of Khademi et al. (29), in 2006, which compares the antimicrobial substantivity of $\mathrm{CHX}$, doxycycline and $\mathrm{NaOCl}$ against E. faecalis. At day 0 the irrigant that has the highest antimicrobial activity is $\mathrm{NaOCl}$, however on days 14, 21, 28, it is CHX that shows the greatest decrease in CFUs with statistically significant differences with respect to the other groups. Another study confirming that the residual effects of CHX are greater than those of $\mathrm{NaOCl}$ is that of Dametto et al. (30) in 2005. In effect, they discovered that at day 0 , unlike the previous study, there are no statistically significant differences between $5.25 \%$ $\mathrm{NaOCl}$ and 2\% CHX both liquid and gel; but on day 7 there are statistically significant differences between $\mathrm{CHX}$ and $\mathrm{NaOCl}$, being the two presentation forms of CHX equally effective in the long term. In 2015, Ferrer et al. (31) decided to see if by lowering the CHX concentration from $2 \%$ to $0.2 \%$ its antimicrobial efficacy was maintained and they also wanted to compare it with the $0.2 \%$ CTR. However, it turned out that it is $2 \% \mathrm{CHX}$ that shows a greater inhibitory capacity at 50 days of its placement with only $34.61 \%$ growth of E. faecalis with statistically significant differences with respect to the other two groups. The $0.2 \% \mathrm{CHX}$ and the CTR obtained a much higher bacterial growth of $69.23 \%$, without statistically significant differences between them (31). Contraries are the results obtained by Baca et al. (19) in 2011. They discovered that $0.2 \%$ of CTR is able to obtain, like CHX at $2 \%, 100 \%$ inhibition of the growth of E. faecalis biofilm in long term, with statistically significant differences with respect to the other groups analyzed. The other irrigating solutions considered were the MA that was found to have a bacterial inhibition of $85.66 \%$, with statistically significant differences with respect to the control group, but not with respect to the results obtained by EDTA, with an inhibition of $64.21 \% ; \mathrm{NaOCl}$ was also analyzed at $2.5 \%$, which led to a decrease of only $18.10 \%$, without statistically significant differences with respect to the control group (19). Another author who wanted to analyze the long-term efficacy of MA at 7\% was Ferrer in 2015 (32). From this study it turned out that the best options in ter$\mathrm{ms}$ of long-term antimicrobial action, 60 days, are the combination of $7 \%$ MA with $2 \%$ CHX, with bacterial growth of $41.66 \%$, and $0.2 \%$ CTR with CHX to $2 \%$, with a growth of $33.33 \%$, without statistically significant differences between them, but with respect to the other groups analyzed, that are: the $\mathrm{NaOCl}$ at $5.25 \%$, which turns out to be the worst, $100 \%$ of bacterial growth, with statistically significant difference with respect to the others, $7 \%$ of MA, which with a $91.66 \%$ growth 
shows statistically significant differences with respect to $\mathrm{CHX}+\mathrm{MA}$ and CHX + CTR, but not with respect to MA + CTR with a growth of $58.33 \%$ (32) . Some authors maintain that $\mathrm{NaOCl}$ achieves such low long-term results because, due to its high surface tension, it is unable to penetrate the dentinal tubules; therefore, it would be convenient to add a detergent as a surfactant substance. This is how Hypoclean ${ }^{\circledR}$ was born, an irrigating solution based on detergents, composed of $5.25 \% \mathrm{NaOCl}$ and two detergents (33). Two other solutions containing detergents are MTAD ${ }^{\circledR}$ and Tetraclean ${ }^{\circledR}$. Among these

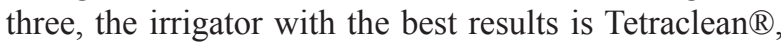
with statistically significant differences with respect to $\mathrm{NaOCl}$, Hypoclean ${ }^{\circledR}$ and MTAD ${ }^{\circledR}(33)$.

-Irrigation techniques

Many times these irrigating solutions are not used alone, but are usually activated with different methods so that they reach the entire canal system and, therefore, eliminate the greatest number of bacteria and organic substances (7). Numerous are the studies that compare the different activation mechanisms between them and with the conventional needle technique. Beus et al. (23), in 2012, compared the effectiveness of ultrasonic passive irrigation (PUI) with active ultrasonic irrigation (NUI) and found that although PUI results in $84 \%$ of negative cultures and NUI in $80 \%$, there are no statistically significant differences between them. However, PUI can present a series of advantages: a more effective removal of pulp and dentin remnants, a greater efficiency when removing bacteria compared with manual irrigation, greater efficiency in curved canals and when cleaning the isthmuses and a greater removal of the dentin compared to the sonic irrigation (34). It has also been shown that PUI has a very good penetration capacity in the dentinal tubules (6). The antibacterial effectiveness of the ultrasonic irrigation is also confirmed by the study by Nakamura et al. (35), in 2017. The authors saw that by activating the irrigating solutions with the ultrasound, in the collected samples, after the same activation, the decrease in the number of bacteria was higher, with statistically significant differences compared to those taken after manual irrigation. However, with regard to endotoxins, no statistically significant differences were found between the two methods used. Paragliola et al. (6), in 2010, evaluated the penetration of $\mathrm{NaOCl}$ when activated with different methods, and saw that the best results, with statistically significant differences, were always obtained by the PUI, in particular by the EMS ${ }^{\circledR}$ and the Satelec ${ }^{\circledR}$, surpassing the activation with manual files, with gutta-percha, with the EndoActivator ${ }^{\circledR}$ and with the Plastic Endo ${ }^{\circledR}$. In contrast, PUI appears to be less effective when assessing apical safety. In fact, in the study by Desai et al. (5), in 2009, the EndoVac ${ }^{\circledR}$ group was the only one that did not cause apical extrusion; however, there are no statistically significant diffe- rences between this technique and the EndoActivator ${ }^{\circledR}$, but there are differences with the ER, manual irrigation and the UI. Therefore, the placement of a microcannula at LT, typical of the EndoVac and thanks to which 50\% of the irrigating substance circulates in the most apical millimeters of the root canals, is an improvement over manual irrigation, although its performance in the apical portion it is not $100 \%$ (5).

Recently, when talking about endodontic irrigation, the concept of PDT has been introduced in order to minimize or eliminate residual bacteria in the root canals. Therefore, several studies compare the antimicrobial efficacy of this technique with the more conventional irrigation techniques (9), with controversial results. The study by Vaziri et al. (36), in 2012, confirmed that the combination of PDT with $2.5 \%$ of $\mathrm{NaOCl}$ is capable of eliminating $100 \%$ of E. faecalis bacteria, leading compared with a statistically significant decrease in CFUs to irrigation with only the PDT or with $2 \% \mathrm{CHX}$. If, on the other hand, the PDT is compared, not with manual irrigation techniques, but with activation techniques, the results are different. In fact, in the study by Xhevdet et al. (37), in 2014, comparing PDT with $\mathrm{NaOCl}$ and PUI combined with $\mathrm{NaOCl}$, it is seen that the combination of PUI and $\mathrm{NaOCl}$ is the one that gives a better antimicrobial action against $E$. faecalis and against $C$. albicans, since it leads to a statistically greater decrease in CFU compared to the other groups analyzed.

Another innovative method, which has been introduced in the market to allow the exchange of irrigating fluids and the elimination of organic tissue and microorganis$\mathrm{ms}$, especially those with a complex internal anatomy, is the PIPS (38). Al Shahrani et al. (38), in 2014, demonstrated that PIPS is useful in increasing the antimicrobial efficacy of $\mathrm{NaOCl}$ because it was found that the largest reduction of E. faecalis colonies occurred in the PIPS group and $6 \% \mathrm{NaOCl}$; however, the three groups analyzed, PIPS with saline solution, $6 \%$ of $\mathrm{NaOCl}$ and PIPS with $\mathrm{NaOCl}$, led to a statistically significant decrease in CFU compared to the control group. Another study confirming that the true antimicrobial efficacy of this method is given by $\mathrm{NaOCl}$, is that of Pedullà et al. (39), in 2012. Indeed, these authors demonstrated that between irrigation with $\mathrm{NaOCl}$ with laser activation and without laser activation there are no statistically significant differences given that both methods lead to a significant decrease in CFU compared with irrigation with distilled water with or without laser activation. However, it is the $\mathrm{NaOCl}$ group with PIPS activation that leads to a greater decrease in bacteria, which confirms the fact that PIPS can be used as an additive method to potentiate the effect of $\mathrm{NaOCl}$ (39). Another study confirming that PIPS does not provide statistically significant differences to conventional irrigation is that of Zhu et al. (7), in 2013. Indeed, these authors found that there are no 
statistically significant differences in the level of antimicrobial efficacy between $\mathrm{CHX}, \mathrm{NaOCl}$ with EDTA and $\mathrm{NaOCl}$ with PIPS (7). Therefore, it can be concluded that PIPS can increase the efficacy of $\mathrm{NaOCl}$, favoring its penetration and giving it a greater bactericidal power (39).

-Clinical protocols

Due to the fact that it is not possible to determine beforehand the treatment of the canal, which microorganisms are present, we can not choose, with consequence, a single irrigator. That is why there is no one ideal and perfect solution for all cases, hence the importance of adopting an irrigation protocol, to achieve maximum disinfection of the root canals. Thus, although $\mathrm{NaOCl}$ possesses many qualities and properties, by itself it is not capable of totally cleaning the root canal system of organic and inorganic remains (1). Therefore, for optimal irrigation, different irrigating solutions have to be combined.

Beus et al. (23), in 2012, presented an action protocol combining several irrigants and choosing PUI activation method (Fig. 1). However, comparing the passive ultra- sonic activation method with the non-ultrasonic activation method, which consists of pouring into the ducts 6 $\mathrm{ml}$ of $1 \% \mathrm{NaOCl}$ with a continuous flow of $2 \mathrm{ml} / \mathrm{min}$, it turns out that there are no statistically significant differences between the two protocols.

On the other hand, the study by Nakamura et al. (35), in 2018, determines that by activating the irrigating solutions with ultrasounds, it is possible to obtain statistically significant differences following the protocol proposed in Figure 2. The differences obtained with the Beus' study are probably due to the amount of irrigant used, in this study they are duplicated with respect to Beus' and to the fact that in the previous study the ultrasonic irrigation was passive while in this study it is active (23) (35). The difference between the two is that in the first the tip of the ultrasound does not come into contact with the dentinal walls, while in the active activation the tip touches the walls and instruments simultaneously (35). On the other hand, the results obtained by Hertel et al. (40), in 2016, are similar to those of Beus: applying a conventional irrigation protocol with $1 \% \mathrm{NaOCl}$ throu-

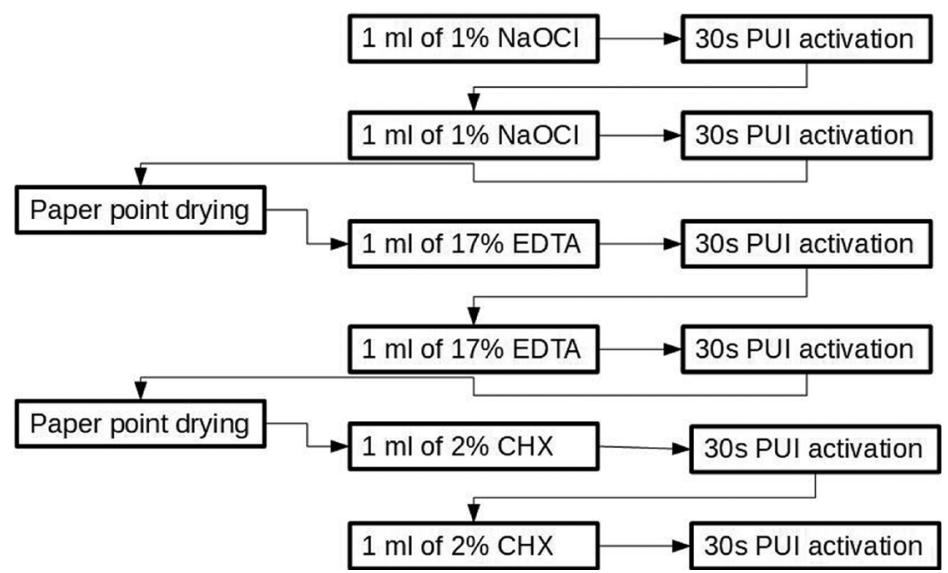

Fig. 1: Irrigation protocol with PUI (23).

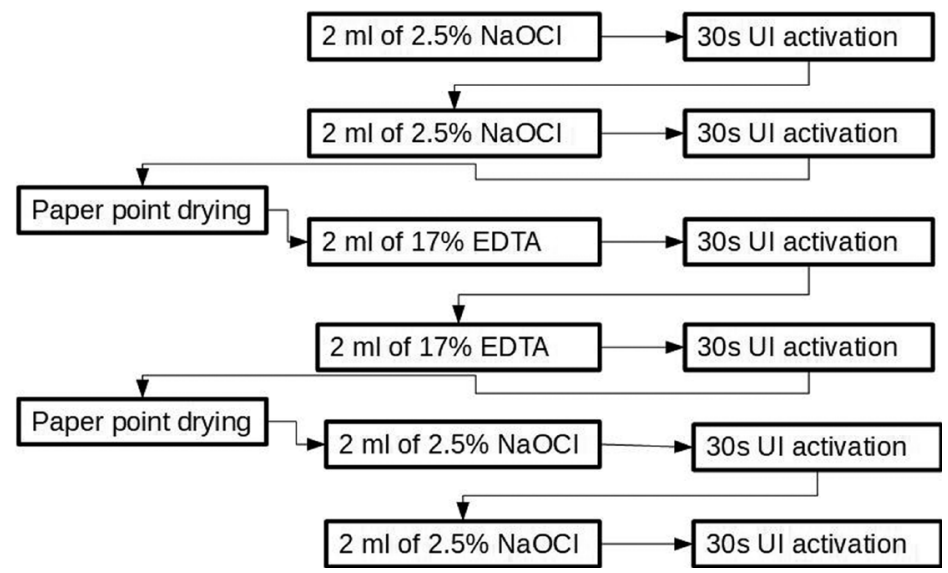

Fig. 2: Irrigation protocol with UI (34). 
ghout the instrumentation and a final wash with $2 \mathrm{ml}$ of $\mathrm{NaOCl}$ during $30 \mathrm{~s}$ there are no statistically significant differences with respect to the PUI protocol. This second protocol consists of combining $1 \%$ of $\mathrm{NaOCl}$ with activation with PUI during the instrumentation followed by a final wash with $2 \mathrm{ml}$ of $1 \%$ of $\mathrm{NaOCl}$ activated during 30 s with PUI and with $2 \mathrm{ml}$ of $20 \%$ of EDTA activated during 30s with PUI. The success rate of the first protocol is $72.6 \%$ while that of the second is $82.8 \%$. The study by Kishen et al. (17), in 2008, on the contrary, states that when EDTA is used as a last irrigator, this increases the number of E. faeclis bacteria adhered, therefore, it is advisable to irrigate, applying in sequence, as last wash, EDTA, $\mathrm{NaOCl}$ and $\mathrm{CHX}$, given that this protocol results in the lowest number of bacteria adhered, or 19\%. Baca et al. (19), however, suggest that, as an irrigation protocol, to achieve the eradication of $E$. faecalis, the following is more indicated: irrigation during the instrumentation with $2.5 \% \mathrm{NaOCl}$, which confers an immediate antimicrobial action, final irrigation with $2.5 \%$ $\mathrm{NaOCl}$, followed by $7 \% \mathrm{MA}$ followed by $0.2 \% \mathrm{CTR}$ or $2 \% \mathrm{CHX}$, which confers $100 \%$ inhibition of bacteria in the long term. Four years later, in 2015, the study by Ferrer et al. (32) confirms that to effectively and in the long term eliminate $E$. faecalis it is convenient to use for the final irrigation the MA at $7 \%$ or the CTR at $0.2 \%$; the only difference marked with the previous study is that Ferrer and col advise to use them always combined with the $\mathrm{CHX}$ at $2 \%$ since the result obtained by this combination shows statistically significant differences with respect to the agents used alone (32).

\section{Conclusions}

The "gold standard" irrigant in terms of immediate antimicrobial efficacy, with statistically significant differences, remains the $\mathrm{NaOCl}$, but without obtaining unanimity on the ideal concentration to be used, which ranges between $0.5 \%$ and $6 \%$. In second position $\mathrm{CHX}$ at $2 \%$, is placed which nevertheless exceeds, with statistically significant differences, $\mathrm{NaOCl}$ and all other solutions available in the market in terms of long-term efficiency. Regarding intracanal medications, there are controversies about the use of $\mathrm{Ca}(\mathrm{OH})_{2}$ alone, the combination of $\mathrm{Ca}(\mathrm{OH})_{2}$ with $\mathrm{CPMC}$ seems promising. The activation method that has been shown to be most effective is ultrasonic activation. PIPS and PDT also lead to a significant decrease in the number of bacteria. However, all these agitation methods are practically comparable with manual irrigation.

The most effective irrigation protocol to eliminate $E$. faecalis, responsible for the majority of endodontic failures consists of: I) Irrigation with $2.5 \% \mathrm{NaOCl}, \mathrm{II}$ ) Choice of LAM, III) Activation of irrigants through ultrasound of the following form: $2 \mathrm{ml}$ of $2.5 \% \mathrm{NaOCl}$ plus 30 s of activation with UI (x2); aspirate $\mathrm{NaOCl} ; 2 \mathrm{ml}$ of $17 \%$ EDTA plus 30 s of activation with UI (x 2); aspire
EDTA; $2 \mathrm{ml}$ of $2.5 \% \mathrm{NaOCl}$ plus $30 \mathrm{~s}$ of activation with UI (x 2), IV) Final wash with $7 \% \mathrm{MA}+2 \% \mathrm{CHX}$ or $7 \%$ $\mathrm{MA}+0.2 \% \mathrm{CTR}+2 \% \mathrm{CHX}$.

\section{References}

1. Kandaswamy D, Venkateshbabu N. Root canal irrigants. J Conserv Dent. 2010;13:256-64.

2. Zehnder M. Root Canal Irrigants. J Endod. 2006;32:389-98.

3. Mohammad Z, Soltani MK, Shalav S. An update on the management of endodontic biofilms using root canal irrigants and medicaments. Iran Endod J. 2014;9:89-97.

4. Peters OA, Laib A, Göhring TN, Barbakow F. Changes in root canal geometry after preparation assessed by high-resolution computed tomography. J Endod. 2001;27:1-6.

5. Desai P, Himel V. Comparative safety of various intracanal irrigation systems. J Endod. 2009;35:545-9.

6. Paragliola R, Franco V, Fabiani C, Mazzoni A, Nato F, Tay FR, et al. Final rinse optimization: influence of different agitation protocols. J Endod. 2010;36:282-5.

7. Zhu X, Yin X, Chang JW, Wang Y, Cheung GS, Zhang C. Comparison of the antibacterial effect and smear layer removal using photon-initiated photoacoustic streaming aided irrigation versus a conventional irrigation in single-rooted canals: an in vitro study. Photomed Laser Surg. 2013;31:371-7.

8. Arslan H, Akcay M, Capar ID, Saygili G, Gok T, Ertas H. An in vitro comparison of irrigation using photon-initiated photoacoustic streaming, ultrasonic, sonic and needle techniques in removing calcium hydroxide. Int Endod J. 2015;48:246-51.

9. Yildirim C, Karaarslan ES, Ozsevik S, Zer Y, Sari T, Usumez A. Antimicrobial efficiency of photodynamic therapy with different irradiation durations. Eur J Dent. 2013;7:469-73.

10. Giardino L, Ambu E, Savoldi E, Rimondini R, Cassanelli C, Debbia EA. Comparative evaluation of antimicrobial efficacy of sodium hypochlorite, MTAD, and Tetraclean against Enterococcus faecalis biofilm. J Endod. 2007;33:852-5.

11. Giardino L, Savoldi E, Ambu E, Rimondini R, Palezona A, Debbia E. Antimicrobial effect of MTDA, Tetraclean, Cloreximid and sodium hypochlorite on three common endodontic pathogens. Indian J Dent Res. 2009;20:391-7.

12. Dunavant TR, Regan JD, Glickman GN, Solomon ES, Honeyman AL. Comparative evaluation of endodontic irrigants against Enterococcus faecalis biofilms. J Endod. 2006;32:527-31.

13. Gomes BPF, Ferraz CC, Vianna ME, Berber VB, Teixeira FB, Souza-Filho FJ. In vitro antimicrobial activity of several concentrations of sodium hypochlorite and chlorhexidine gluconate in the elimination of Enterococcus faecalis. Int Endod J. 2001;34:424-8.

14. Menezes MM, Valera MC, Jorge AO, Koga-Ito CY, Camargo CH, Mancini MNG. In vitro evaluation of the effectiveness of irrigants and intracanal medicaments on microorganisms within root canals. Int Endod J. 2004;37:311-9.

15. Hope CK, Garton SG, Wang Q, Burnside G, Farrelly PJ. A direct comparison between extracted tooth and filter-membrane biofilm models of endodontic irrigation using Enterococcus faecalis. Arch Microbiol. 2010;192:775-81.

16. Endo MS, Ferraz CC, Zaia AA, Almeida JF, Gomes BP. Quantitative and qualitative analysis of microorganisms in root-filled teeth with persistent infection: Monitoring of the endodontic retreatment. Eur J Dent. 2013;7.

17. Kishen A, Sum CP, Mathew S, Lim CT. Influence of Irrigation Regimens on the Adherence of Enterococcus faecalis to Root Canal Dentin. J Endod. 2008;34:850-4.

18. Arias-Moliz MT, Ferrer-Luque CM, Espigares-Rodríguez E, Liébana-Ureña J, Espigares-García M. Bactericidal activity of phosphoric acid, citric acid, and EDTA solutions against Enterococcus faecalis. Oral Surgery, Oral Med Oral Pathol Oral Radiol Endod. 2008;106:849.

19. Baca P, Junco P, Arias-Moliz MT, González-Rodríguez MP, Ferrer-Luque CM. Residual and antimicrobial activity of final irriga- 
tion protocols on enterococcus faecalis biofilm in dentin. $\mathrm{J}$ Endod. 2011;37:363-6.

20. Ferrer-Luque CM, Arias-Moliz MT, González-Rodríguez MP, Baca P. Antimicrobial activity of maleic acid and combinations of cetrimide with chelating agents against enterococcus faecalis biofilm. J Endod. 2010;36:1673-5.

21. Siqueira JF, Rôças IN. Clinical implications and microbiology of bacterial persistence after treatment procedures. J Endod. 2008;34:1291-301.

22. Evans M, Davies JK, Sundqvist G FD. Mechanisms involved in the resistance of Enterococcus faecalis to calcium hydroxide. Int Endod J. 2002;35:221-8.

23. Beus C, Safavi K, Stratton J, Kaufman B. Comparison of the effect of two endodontic irrigation protocols on the elimination of bacteria from root canal system: A prospective, randomized clinical trial. J Endod. 2012;38:1479-83.

24. Lima KC, Fava LRG, Siqueira JF. Susceptibilities of Enterococcus faecalis biofilms to some antimicrobial medications. J Endod. 2001;27:616-9.

25. Siqueira JF, Magalhães KM, Rôças IN. Bacterial reduction in infected root canals treated with $2.5 \% \mathrm{NaOCl}$ as an irrigant and calcium hydroxide/camphorated paramonochlorophenol paste as an intracanal dressing. J Endod. 2007;33:667-72.

26. Siqueira JF, Guimarães-Pinto T, Rôças IN. Effects of chemomechanical preparation with $2.5 \%$ sodium hypochlorite and intracanal medication with calcium hydroxide on cultivable bacteria in infected root canals. J Endod. 2007;33:800-5.

27. Siqueira JF, Rôças LN, Magalhães FAC, de Uzeda M. Antifungal effects of endodontic medicaments. Aust Endod J. 2001;27:112-4.

28. Silveira AM, Lopes HP, Siqueira JF Jr, Macedo B, Consolaro A. Periradicular repair after two-visit endodontic treatment using two different intracanal medications compared to single-visit endodontic treatment. Braz Dent J. 2007;18:299-304.

29. Khademi AA, Mohammadi Z, Havaee A. Evaluation of the antibacterial substantivity of several intra-canal agents. Aust Endod J. 2006;32:112-5.

30. Dametto FR, Ferraz CC, Gomes BP, Zaia AA, Teixeira FB, de Souza-Filho FJ. In vitro assessment of the immediate and prolonged antimicrobial action of chlorhexidine gel as an endodontic irrigant against Enterococcus faecalis. Oral Surg Oral Med Oral Pathol Oral Radiol Endod. 2005;99:768-72.

31. Ferrer-Luque CM, Arias-Moliz MT, Ruíz-Linares M, Martínez-García ME, Baca P. Residual activity of cetrimide and chlorhexidine on Enterococcus faecalis-infected root canals. Int J Oral Sci. 2014;6:46-9.

32. Ferrer-Luque CM, González-Castillo S, Ruiz-Linares $\mathrm{M}$, Arias-Moliz MT, Rodríguez-Archilla A, Baca P. Antimicrobial residual effects of irrigation regimens with maleic acid in infected root canals. J Biol Res. 2015;22:1.

33. Mohammadi Z, Mombeinipour A, Giardino L, Shahriari S. Residual antibacterial activity of a new modified sodium hypochlorite-based endodontic irrigation solution. Med Oral Patol Oral Cir Bucal. 2011;16:588-92.

34. Van Der Sluis LWM, Versluis M, Wu MK, Wesselink PR. Passive ultrasonic irrigation of the root canal: A review of the literature. Int Endod J. 2007;40:415-26.

35. Nakamura VC, Pinheiro ET, Prado LC, Silveira AC, Carvalho APL, Mayer MPA. Effect of ultrasonic activation on the reduction of bacteria and endotoxins in root canals: a randomized clinical trial. Int Endod J. 2018; 51:e12-e22.

36.Vaziri S, Kangarlou A, Shahbazi R, Nazari-Nasab A, Naseri M. Comparison of the bactericidal efficacy of photodynamic therapy, 2,5\% sodium hypochlorite, and $2 \%$ chlorhexidine against Enterococcous faecalis in root canals; an in vitro study. Dent Res J (Isfahan). 2012;9:47-53.

37. Xhevdet A, Stubljar D, Kriznar I, Jukic T, Skvarc M, Veranic P, et al. The disinfecting efficacy of root canals with laser photodynamic therapy. J Lasers Med Sci. 2014;5:19-26.

38. Al Shahrani M, DiVito E, Hughes C V., Nathanson D, Huang GT.
Enhanced removal of Enterococcus faecalis biofilms in the root canal using sodium hypochlorite plus photon-induced photoacoustic streaming: an in vitro study. Photomed Laser Surg. 2014;32:260-6.

39. Pedullà E, Genovese C, Campagna E, Tempera G, Rapisarda E. Decontamination efficacy of photon-initiated photoacoustic streaming (PIPS) of irrigants using low-energy laser settings: an ex vivo study. Int Endod J. 2012;45:865-70.

40. Hertel M, Sommer K, Kostka E, Imiolczyk SM, Ballout H, Preissner S. Outcomes of endodontic therapy comparing conventional sodium hypochlorite irrigation with passive ultrasonic irrigation using sodium hypochlorite and ethylenediaminetetraacetate. A retrospective analysis. Open Dent J. 2016;10:375-81.

\section{Conflicts of Interest}

The authors have declared that no conflict of interest exist. 